\title{
PERANCANGAN SISTEM INFORMASI GEOGRAFIS PENANGANAN IZIN MENDIRIKAN BANGUNAN
}

\author{
Ika Arum Puspita, Budi Sulistyo, Devi Pratami \\ Program Studi Teknik Industri Fakultas Rekayasa Industri, Telkom University, Bandung, Indonesia \\ ikaarumpuspita@telkomuniversity.ac.id, budisulistyo@telkomuniversity.ac.id, devipratami@telkomuniversity.ac.id
}

\begin{abstract}
Abstrak - PEMDA (Pemerintah Daerah) diharapkan memiliki Perda bangunan gedung yang mengatur tentang penataan bangunan dan lingkungan. Pada kenyataannya pembangunan bangunan masih banyak yang dibangun tanpa dilengkapi dengan Izin Mendirikan Bangunan (IMB), selain itu masih banyak bangunan yang dibangun tanpa memperhatikan daya dukung lingkungan yang menyebabkan rawan banjir, longsor, kumuh dan rawan kriminalitas. Penelitian ini merupakan perancangan aplikasi yang dapat mempermudah pemerintah dalam mengontrol bangunan yang mmiliki IMB. Aplikasi ini berisikan data bangunan, tata ruang, penggunaan lahan, dan fungsionalitas bangunan. Dari sistem ini akan ditampilkan informasi bangunan beserta kriteria atau fungsionalitas bangunan yang sesuai dengan IMB-nya. Fungsi lain dari aplikasi sistem informasi geografis (SIG) sebagai salah satu pendukung pengambilan keputusan perizinan pengajuan pembuatan IMB. Selain itu juga dapat digunakan untuk pendokumentasian data kepemilikan IMB menadi satu data base.

Kata kunci- sistem informasi geografis, izin mendirikan bangunan
\end{abstract}

\section{PENDAhUlUaN}

Sistem Informasi Geografis (SIG) merupakan sebuah sistem yang memberikan informasi yang berkaitan dengan data spasial yakni kondisi geografis suatu wilayah. Sistem ini dapat memetakan suatu tempat baik berupa batas wilayah, jalan, sungai, maupun kondisi geografis lainnya [1]. Sistem ini merupakan sistem komputerisasi yang memudahkan proses memasukkan data, menganalisis, dan menyajikan informasi terkait data georeferensi [2]

Pemerintah daerah diharapkan memiliki Perda bangunan gedung sejak tahun 2010. Hal ini sebagai tindak lanjut Undang-Undang Nomor 28 tahun 2002 tentang bangunan gedung dan Peraturan Pemerintah Nomor 36 tahun 2005. Peraturan ini berisikan pengaturan dan pentertiban bangunan yang sesuai dengan fungsionalitasnya dengan kata lain setiap bangunan harus memiliki IMB sesuai dengan peruntukannya. Fakta dilapangan, pembangunan bangunan banyak yang belum memiliki Izin Mendirikan Bangunan (IMB), atau bangunan dengan IMB tetapi masih belum memenuhi persyaratan teknis. Kondisi ini berdampak pada bangunan yang kurang handal terhadap gempa, rawan kebakaran, rawan banjir, longsor, kumuh, dan rawan kriminalitas.

Di Kabupaten Bandung penertiban bangunan yang tidak memiliki IMB dilakukan dengan cara memberikan teguran. Penertiban bangunan akan dilakukan untuk bangunan yang mengganggu hubungan bermasyarakat, ketertiban masyarakat, dan lalu lintas. Komplain masyarakat akan diproses dengan dilakukan pengecekan IMB-nya, apabila tidak memiliki IMB atau memiliki IMB namun fungsionalitas dan karekteristik bangunan tidak sesuai yang terdaftar maka pemerintah akan memberikan teguran untuk merombak bangunan tersebut.

IMB akan diberikan apabila pihak pengaju melengkapi semua persyaratan, salah satu syarat yang harus dipenuhi adalah karakteristik bangunan yang sesuai dengan tata ruang yang telah dicanangkan [3]. Namun, saat ini informasi yang diperoleh masyarakat mengenai pengajuan IMB masih sangat kurang, kepastian diperbolehkannya IMB memerlukan waktu dalam proses pengecekan kesesuaian jenis bangunan yang diajukan dengan penggunaan lahan yang dicanangkan. Setelah IMB diberikan, proses pendokumentasian masih belum baik karena berkas belum terkomputerisasi.

Penelitian ini merancang aplikasi sistem informasi geografis (SIG) dalam penanganan IMB. Sistem ini digunakan oleh masyarakat dan Pemerintah Kabupaten Bandung. Masyarakat mendapatkan informasi mengenai persyaratan pengajuan IMB sedangkan Dinas Pemukiman dan Tata Ruang Kabupaten Bandung dapat menggunakan sistem ini untuk mendokumentasikan data pengaju IMB. Aplikasi ini berisikan data bangunan yang memiliki IMB di Kecamatan Dayeuhkolot, data tata ruang, dan penggunaan lahan beserta ketentuan fungsionalitas bangunan yang diperuntukkan di suatu wilayah. Dengan adanya data-data tersebut maka dapat dilakukan analisis keruangan, data tersebut diolah oleh sistem sehingga mempercepat proses pengolahan data. Informasi yang cepat sangat diperlukan pada keadaan ini. Informasi yang cepat diperoleh akan mempercepat pula pengambian keputusan [4]

Aplikasi ini dapat mendokumentasikan data pengaju IMB menjadi satu database. Hal ini juga diharapkan dapat menunjang tata ruang yang lebih baik ke depannya seiring bertambahnya bangunan yang akan dibangun.

\section{LANDASAN TEORI}

\subsection{Sistem Informasi Geografis}

Sistem Informasi Geografis (SIG) atau yang dikenal dengan Geographic Information System (GIS) adalah sistem yang berbasiskan komputer yang digunakan untuk menyimpan dan memanipulasi data-data geografis. Dari definisi jika 
diperhatikan maka, SIG dapat diuraikan menjadi beberapa subsistem yang terdapat pada Gambar 1.

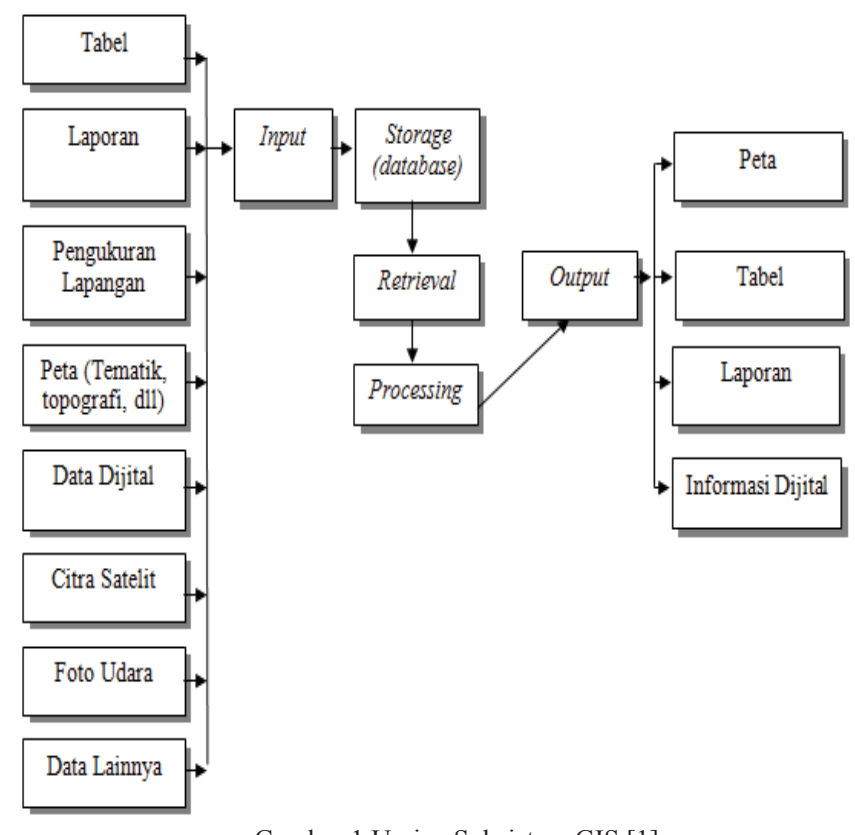

Gambar 1 Uraian Subsistem GIS [1]

SIG merupakan sistem kompleks yang biasanya terintegrasi dengan lingkungan sistem-sistem komputer yang lain ditingkat fungsional dan jaringan.

\subsection{MapServer}

MapServer merupakan salah satu lingkungan pengembangan (perangkat lunak) open-source yang digunakan untuk mengembangkan aplikasi-aplikasi internetbased yang melibatkan (tampilan) data spasial (peta dijital) [5].

\subsubsection{Arsitektur MapServer}

Aplikasi MapServer dasar terdiri atas komponenkomponen sebagai berikut [6]:

a. Map File

Map File merupakan sebuah konfigurasi data yang terstruktur yang digunakan pada MapServer. Map File mendefinisikan area-area pada peta dan juga menentukan input-an dan output-an kepada program MapServer. Selain itu Map File juga berfungsi untuk mendefinisikan lapisan layer yang digunakan pada MapServer yang meliputi data atribut, proyeksi peta, dan simbol-simbol. Map File harus memiliki format .Map untuk dapat diidentifikasi oleh MapServer.

b. Data Geografis

MapServer didukung oleh beberapa tipe peta atau data geografis. Format dasar yang digunakan oleh MapServer adalah Shapefile yang dimiliki oleh ESRI.

c. Halaman HTML

Halaman HTML merupakan bagian yang menghubungkan antara pengguna dengan aplikasi MapServer secara langsung, sehingga aplikasi MapServer menjadi lebih interaktif dan mudah digunakan.

\section{d. Template File}

Template File merupakan bagian pada MapServer yang mengontrol tampilan dari peta dan legenda pada browser. Dengan adanya Template File maka pengguna dapat berinteraksi dengan aplikasi MapServer seperti zoom dan query.

\section{e. MapServer CGI}

MapServer CGI merupakan kode binary atau berupa file eksekusi yang menerima permintaan dan kemudian menampilkan gambar sebagai tampilan.

f. HTTP Server

HTTP Server sebagai penyedia dan penyimpan halaman HTML ketika diakses oleh browser pengguna. Contoh dari HTTP Server adalah Apache atau IIS.

\section{MODEL PENELITIAN}

Penelitian ini meliputi beberapa variabel yang mendukung permasalahan yang di gambarkan pada Gambar 2.

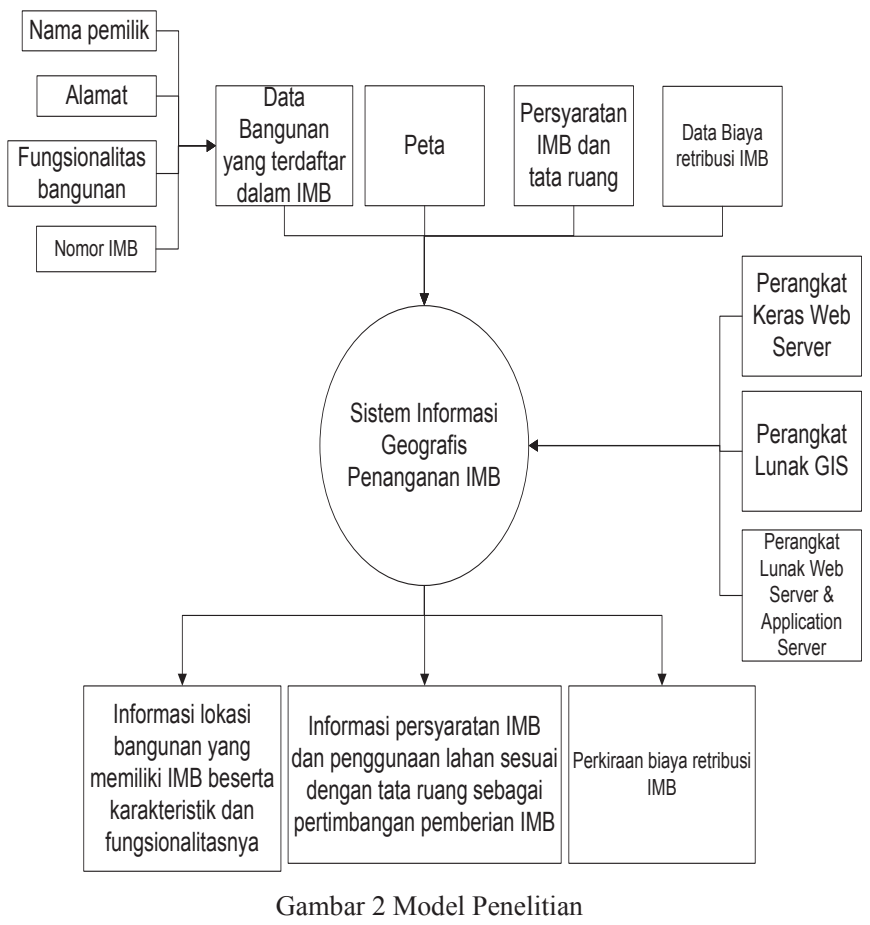

Berdasarkan model penelitian dapat dilihat bahwa terdapat beberapa variabel data spasial dan atribut yang berperan dalam pembuatan sistem informasi ini. Data spasial berupa peta wilayah, sedangkan data atribut berupa data bangunan berIMB, persyaratan IMB, penggunaan lahan sesuai dengan tata ruang, dan data biaya retribusi IMB.

\section{ANALISIS DAN PEMBAHASAN}

\subsection{Diagram Konteks}

Proses perancangan sistem dimulai dengan pembuatan Diagram Aliran Data (DAD) level 0 atau diagram konteks. Diagram konteks adalah diagram yang menggambarkan hubungan antara entitas-entitas yang terdapat di luar sistem dengan sistem, selain itu juga digambarkan masukan dan 
keluaran sistem. Entitas yang terdapat dalam Sistem Informasi Geografis ini adalah admin dan user. Admin merupakan staf pemerintahan dan user adalah masyarakat. Diagram konteks level 0 ditunjukkan oleh Gambar 3.

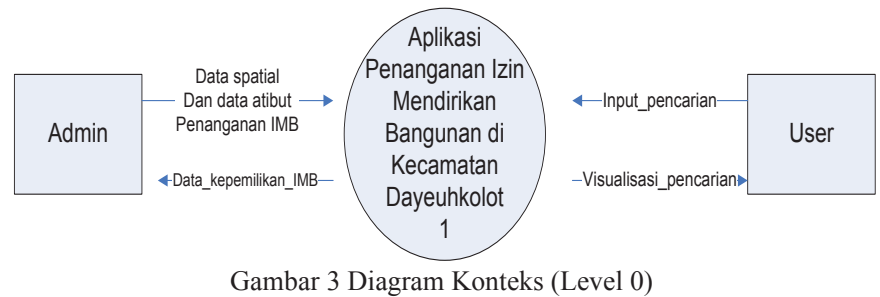

\subsection{Diagram Aliran Data}

Perancangan Sistem Informasi ini mempunyai proses utama yang terdiri atas:

1. proses pencarian lokasi,

2. proses pengolahan data layer,

3. proses penampilan data,

4. proses penampilan lokasi,

5. proses perhitungan biaya retribusi IMB, dan

6. proses registrasi IMB.

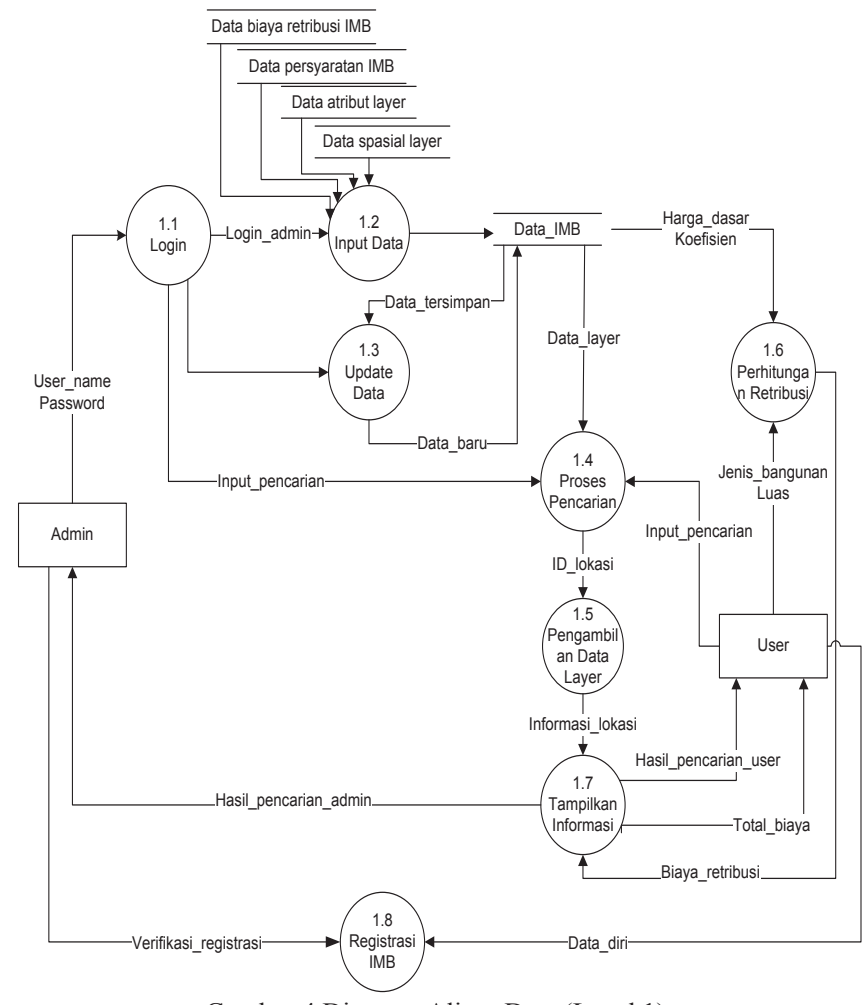

Gambar 4 Diagram Aliran Data (Level 1)

Diagram Aliran Data Level 1 proses utama sistem informasi geografis pada penelitian ini digambarkan pada Gambar 4. Proses nomor 4 merupakan proses pencarian (query), proses ini dapat diakses untuk mencari data rumah yang memiliki IMB sehingga akan ditampilkan informasi terkait IMB. Proses pencarian ini juga dapat digunakan untuk pencarian lokasi dan peruntukan lahan sehingga user dapat mengakses untuk melihat peruntukan lahan pada saat akan melakukan pengajuan IMB. Diagram Aliran Data proses pencarian ditunjukkan pada Gambar 5. Proses nomor 6 yakni perhitungan retribusi merupakan proses dimana user dapat melakukan simulasi besarnya biaya yang harus dikeluarkan pada saat pengajuan IMB. Perhitungan yang dilakukan oleh sistem mengacu pada perhitungan yang dilakukan oleh pemerintah daerah. Diagram aliran data proses perhitungan retribusi ditunjukkan pada Gambar 6 .

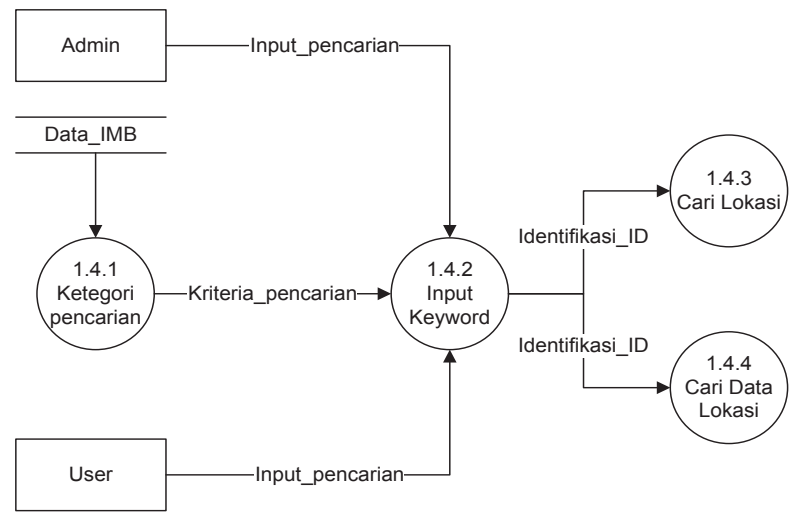

Gambar 5 Diagram Aliran Data Level 2 Proses 4

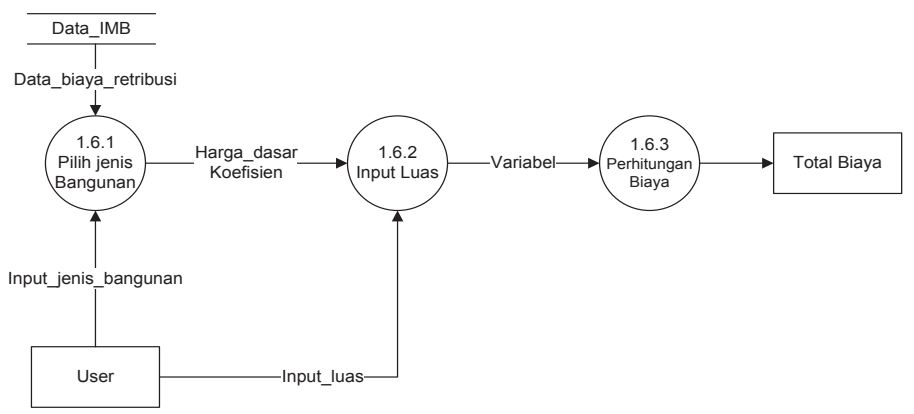

Gambar 6 Diagram Aliran Data Level 2 Proses 6

\subsection{Entity Relational Diagram}

Gambar 7 menunjukkan ERD yang dimiliki oleh setiap wilayah.

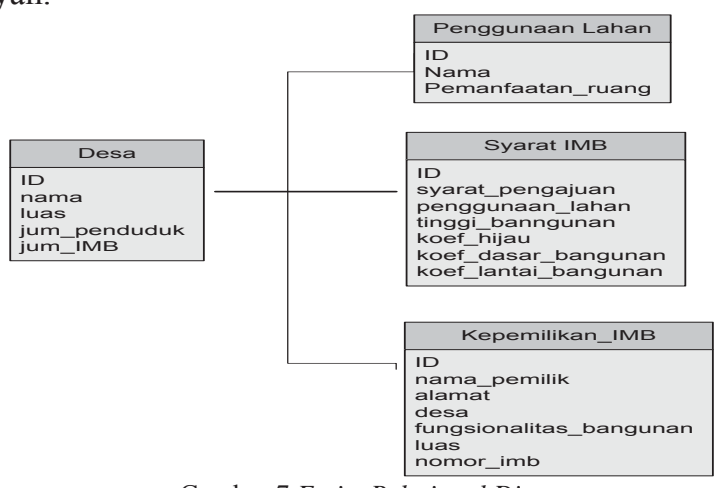

Gambar 7 Entity Relational Diagram

\subsection{Visualisasi}

Proses visualisasi terbagi menjadi dua jenis, yakni berupa peta lokasi dan visualisasi infomasi yang berupa tabel informasi maupun hasil perhitungan. 


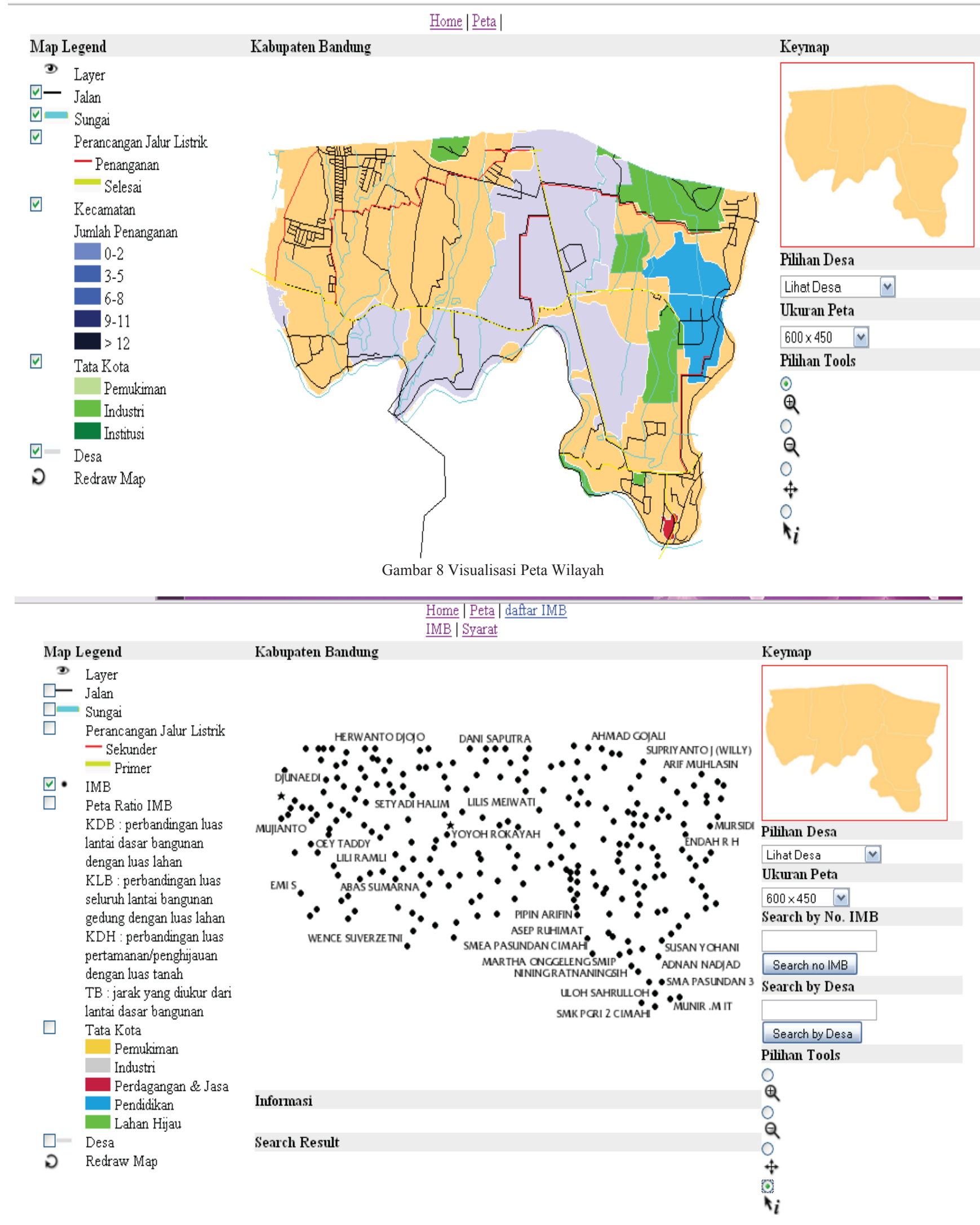

Gambar 9 Visualisasi Persebaran Bangunan ber-IMB 
Gambar 8 merupakan halaman web yang digunakan oleh PEMDA untuk melakukan pengecekan peruntukan lahan, terdapat pilihan menampilkan layer bangunan yang menampilkan bangunan serta status IMB yang dimiliki, bangunan yang tidak memiliki IMB pada peta spasial bangunan akan ditandai dengan warna merah. Keterangan terkait IMB yang dimiliki ditunjukkan pada Gambar 10.

Persebaran peta bangunan yang memiliki IMB ditunjukkan pada Gambar 9. Peta bangunan ini memberikan informasi dengan cepat kepada pemerintah saat melakukan pengecekan data. Adapun informasi peruntukan lahan ditunjukkan pada Gambar 11. Peruntukan lahan dapat memberikan informasi yang mendukung pengambilan keputusan pengajuan IMB di suatu daerah akan di ACC atau tidak terkait persyaratan jenis bangunan terhadap kesesuaian dengan peruntukan lahan

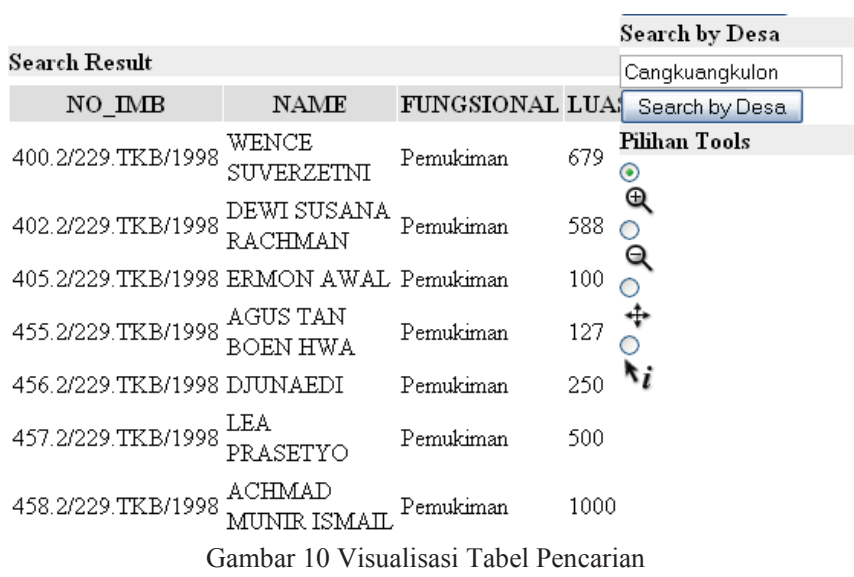
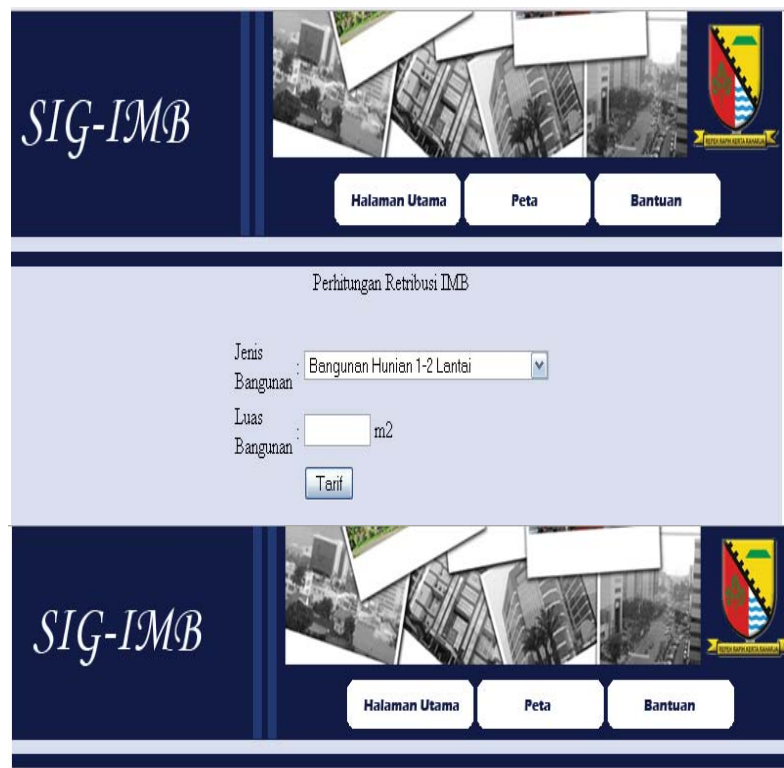

Perhitungan Retribusi IMB

Taif Mendiukan Banguman : Rp. 450000

Gambar 12 Visualisasi Perhitungan Retribusi

Gambar 12 merupakan halaman yang dapat diakses oleh user (masyarakat). Dengan perhitungan retribusi, pihak pemerintah maupun masyarakat dapat secara transparan mengetahui biaya yang harus dibayarkan untuk pengajuan IMB yang diajukan.

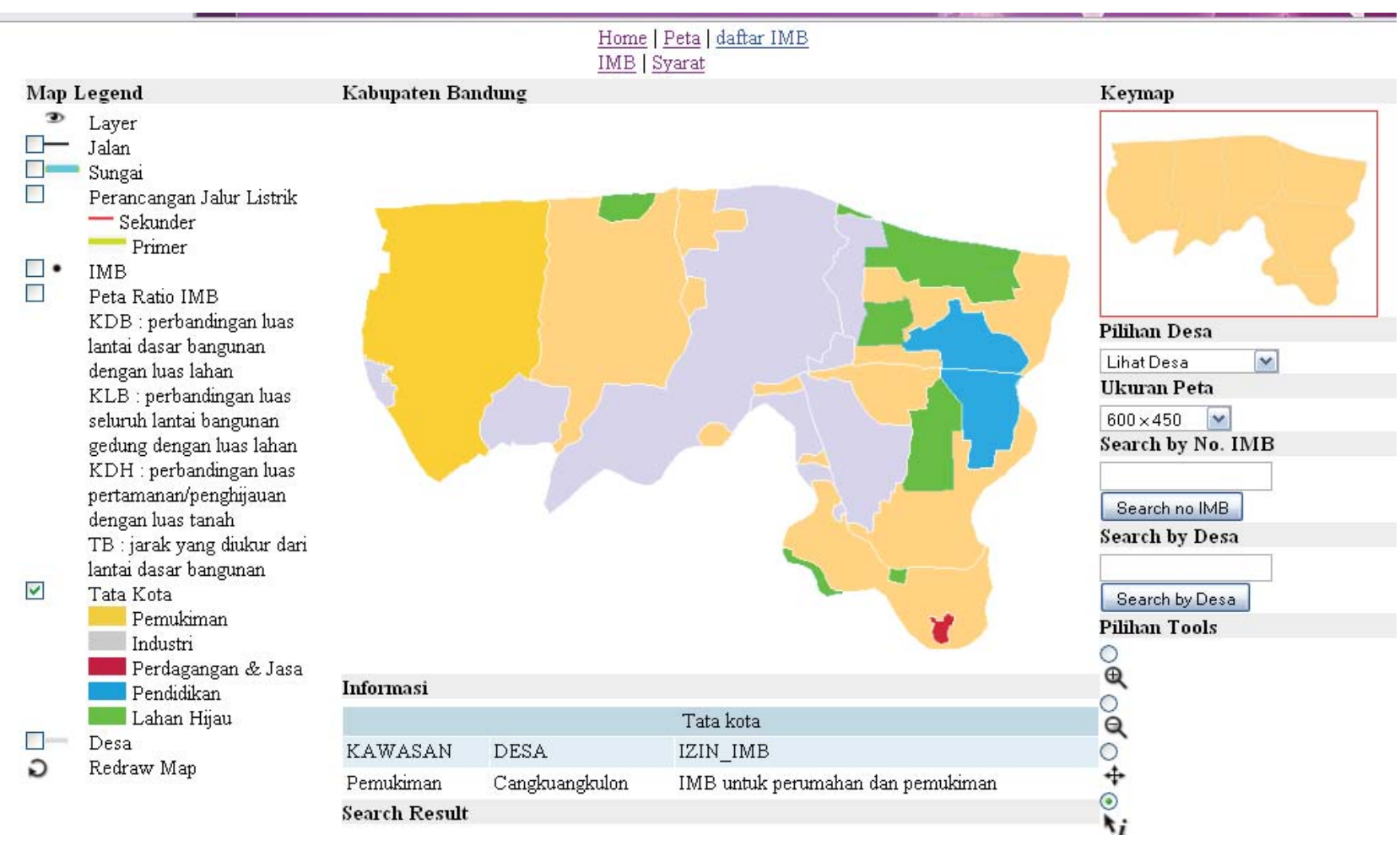

Gambar 11 Visualisasi Tata Kota (Peruntukan Lahan) 

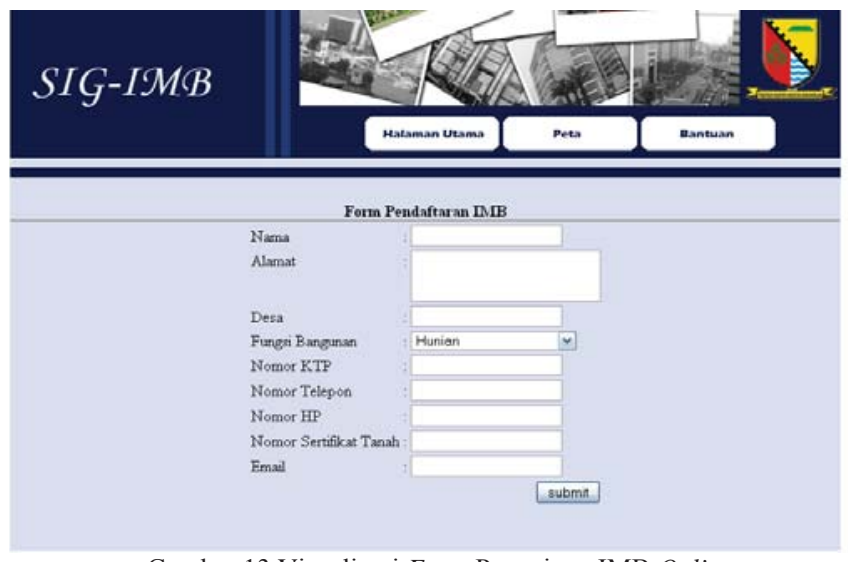

Gambar 13 Visualisasi Form Pengajuan IMB Online

Gambar 13 merupakan halaman yang dapat diakses oleh user (masyarakat) untuk mengajukan IMB secara online. Setelah proses submit, aka nada notif kepada pemerintah untuk melakukan verifikasi. Untuk memverifikasi pemerintah dapat mencocokan syarat pengajuan dan peruntukan lahan sesuai yang terdapat pada sistem yang telah dibuat. Kemudian terdapat notifikasi ACC oleh pemerintah sampai ke penyimpanan data IMB ke database.

\subsection{Analisis Kekuatan dan Kelemahan Sistem}

\subsubsection{Kekuatan Sistem}

1. Sistem ini mampu melakukan memberikan informasi mengenai letak suatu bangunan yang memiliki IMB beserta data kepemilikannya sehingga dapat dengan mudah dan cepat untuk mencari informasi mengenai data kepemilikan IMB.

2. Sistem ini dapat digunakan untuk pencarian suatu lokasi yang disertai dengan menampilkan syarat pengajuan IMB di lokasi tersebut.

3. Sistem ini dapat menampilkan informasi penggunaan lahan yang telah dipetakan dan dapat memberikan keterangan mengenai bangunan yang diperbolehkan dibangun di daerah tersebut.

4. Sistem ini dapat digunakan sebagai data base pendokumentasian data kepemilikan IMB.

5. Sistem ini memiliki kemampuan untuk mengatur tampilan layer yang ada, dimana layer tersebut dapat diatur visibilitasnya.

6. Sistem ini memberikan informasi kepada user mengenai perkiraan biaya retribusi IMB dengan jenis bangunan tertentu dan luas bangunan yang di-input-kan oleh user.

7. Sistem ini digunakan untuk pendaftaran IMB secara Online, hal ini merupakan informasi awal yang memudahkan user untuk mengurus pengajuan IMB selanjutnya.

8. Sistem ini dapat diakses multi user dengan menggunakan server yang ada dapat melayani beberapa user sekaligus.

\subsubsection{Kelemahan Sistem}

1. Akurasi posisi yang ditampilkan dalam aplikasi ini masih belum akurat karena pada penelitian ini tidak memperhatikan koordinat dan titik kilometer dari prasarana jalan dalam penanganan, akan tetapi pada kenyataannya dengan suatu survey dan penentuan toleransi, keakuratan posisi dapat diperbaiki.

2. Sistem ini masih berupa model, apabila akan diaplikasikan perlu adanya pengubahan data peta dan persyaratan IMB namun tidak perlu mengubah logika proses yang ada.

\subsubsection{Analisis Hasil Verifikasi}

Verifikasi untuk sistem ini secara umum dilihat dari beberapa aspek, yakni:

1. Tingkat kemudahan penggunaan aplikasi:

responden dengan jawaban baik sebanyak $70 \%$ dan jawaban cukup 30\% sehingga dapat disimpulkan bahwa sistem ini sudah cukup mudah dalam penggunaannya.

2. Tingkat kemudahan pemahaman fitur: responden dengan jawaban baik sebanyak $70 \%$ dan jawaban cukup $30 \%$ sehingga dapat disimpulkan bahwa fitur sistem ini sudah cukup mudah untuk dipahami.

3. Tingkat kemudahan pencarian informasi: responden dengan jawaban baik sebanyak $60 \%$ dan jawaban cukup $25 \%$ sehingga dapat disimpulkan bahwa sistem ini dapat memberikan kemudahan bagi pihak admin dalam pencarian informasi yang diinginkan.

4. Infomasi yang disajikan:

responden dengan jawaban baik sebanyak $60 \%$, jawaban cukup 30\% dan 10\% menjawab kurang sehingga masih perlu adanya penambahan informasi mengenai data IMB sehingga sistem akan lebih baik lagi dalam menampilkan data IMB.

5. Kelengkapan fungsi:

Responden dengan jawaban baik sebanyak 50\% dan menjawab cukup 50\% sehingga dapat disimpulkan bahwa fungsi yang ada pada sistem ini sudah cukup.

6. Desain aplikasi:

responden dengan jawaban baik sebanyak 60\%, jawaban cukup $30 \%$ dan $10 \%$ menjawab kurang sehingga masih perlu adanya penambahan tampilan desain agar lebih menarik.

7. Tepat guna (hasil sesuai dengan tujuan): responden dengan jawaban baik sebanyak $80 \%$ dan jawaban cukup $20 \%$ sehingga dapat disimpulkan bahwa sistem ini dapat memberikan manfaat kepada pihak admin dalam proses penanganan IMB.

\section{KESIMPULAN}

Kesimpulan yang dapat diambil dari hasil perancangan sistem ini adalah sebagai berikut.

1. Mampu menampilkan visualisasi data spasial berupa peta wilayah baik berupa kondisi geografis wilayah, pemetaan tata ruang dan penggunaan lahan.

2. Mampu menampilkan data atribut peta tiap layer yang berisikan informasi berkaitan dengan IMB.

3. Mampu melakukan pencarian dan memvisualisasikan informasi hasil pencarian.

4. Mampu memberikan informasi kepada user yang merupakan masyarakat umum mengenai hal-hal yang berhubungan dengan persyaratan pengajuan IMB dan 
perkiraan biaya retribusinya maupun pendaftaran IMB melalui sistem Online.

5. Dapat digunakan sebagai pendokumentasian data pemilik IMB.

6. Menjadi faktor pendukung dalam keputusan pemberian IMB berdasarkan peta wilayah pemetaan tata ruang dan peruntukannya.

7. Aplikasi yang dirancang sudah memiliki fungsi yang tepat guna atau sesuai dengan sasaran, dapat memberikan informasi mengenai IMB dengan penggunaan fitur yang mudah dipahami dan mudah digunakan.

Saran bagi penelitian selanjutnya adalah:

1. melengkapi data spasial atau gambar peta yang ada agar dapat merepresentasikan keadaan yang sesungguhnya;

2. melengkapi data bangunan yang ada;

3. akurasi posisi dari objek yang ditampilkan dibuat lebih akurat agar dapat merepresentasikan skala dalam ukuran yang sesungguhnya.

\section{DAFTAR PUSTAKA}

[1] Prahasta, E. 2001. Konsep-konsep Dasar Sistem Informasi Geografis. Bandung: Informatika.

[2] Hung, K.C., Kalantari, M., dan Rajabifard, A., 2016. "Methods for assessing the credibility of volunteered geographic information in flood response: A case study in Brisbane, Australia". Applied Geography (68) 37-47.

[3] Dinas Pemukiman dan Tata Wilayah. 2007. Pedoman Teknis: Penerbitan Izin Mendirikan Bangunan (IMB). Bandung.

[4] Lepuschitz, E. 2015. "Geographic Information Systems in Mountain Risk and Disaster Management". Applied Geography (63) 212-219.

[5] Nuryadin, R. 2005. Panduan Menggunakan MapServer. Bandung : Penerbit Andi.

[6] Prahasta, E. 2007. Membangun Aplikasi Web-Based GIS dengan MapServer. Bandung: Informatika. 